\title{
La opinión pública, "héroe" de la política: la contribución de Jacques Necker
}

\author{
Esteban López-Escobar \\ Profesor ordinario de Opinión Pública. Universidad de Navarra
}

\section{Resumen:}

Jacques Necker, el ministro suizo-francés de finanzas, jugó un papel decisivo en la consolidación de la opinión pública como una fuerza política y también como una noción intelectual. No solamente publicó las cuentas de la monarquía francesa, sino que además escribió De l'administration des finances en France, donde expuso sus ideas sobre la opinión pública; y el libro fue un best-seller en el siglo XVIII. Pero, como ha afirmado la hija de Necker, la religión era aún más importante para él que la opinión pública. Este trabajo no solo se ocupa de la bibliografía más reciente sobre Necker, sino que además presta atención a la relación, tan importante e inadvertida hasta ahora, de la religión y la opinión pública en sus obras.

Palabras clave:

Necker, opinión pública, religión

Abstract:

Jacques Necker, the Swiss-French minister of finances, played a decisive role in the consolidation of public opinion as a political force and as an intellectual concept. He has not only published the French monarchy's accounts, but also wrote De l'administration des finances en France, that includes his ideas on public opinion and became a $18^{\text {th }}$ century bestseller. But, as Necker's daughter explained, religion was before public opinion for him. This paper not only deals with the most recent literature on Necker, but also addresses to this important and till now unnoticed relation of public opinion and religion in his works.

Keywords:

Necker, public opinion, religion 


\section{Introducción}

“Tanto los historiadores que han escrito de 'la supremacía de la opinión pública', como los que han escrito de la naissance d'un monstre (Fay, 1965) han estado de acuerdo en que el final del siglo XVIII y el comienzo del XIX han visto cambios en Europa occidental y en otros lugares que marcaron la llegada de la opinión pública como una fuerza significativa" (Gunn, 1983: 260).

"La opinión, villana de la filosofía, se convirtió en la opinión pública, héroe de la política", dice Peters (1995: 6), aludiendo a la transformación producida en este dominio a lo largo del siglo XVIII, especialmente en su último tercio, y en los comienzos del siglo XIX. Baker (1990: 24-25), remontándose aún más en el tiempo, concreta que, en las décadas de 1750 y 1760, "la política se salió del molde absolutista. La opinión se convirtió en opinión pública: ya no una función social, sino una categoría política, el tribunal du public, el tribunal final de apelación tanto para la autoridad monárquica como para sus críticos". Y, como él mismo advierte (1990: 9), "con la Revolución el centro sagrado del poder fue reconfigurado simbólicamente; la persona pública del soberano fue desplazada por la persona soberana del público; lèse-majesté fue sustituida por lèse-nation".

Gunn (1983: 261) y otros han documentado la utilización temprana de expresiones como "the opinion of the people” en Gran Bretaña hacia 1720, refiriéndose a la voz del pueblo en relación a los asuntos políticos, mientras que "public opinion" se utilizaba en referencia a cómo la opinión de los otros podía afectar a la conducta personal, idea que se corresponde con lo que propuso Locke al tratar de la ley de la opinión o de la reputación, de la virtud y el vicio, o también la ley de la moda, o de la censura privada (1690: 475 ss.). Sin embargo, aunque la investigación de los últimos decenios sitúa a Inglaterra como cuna del concepto de opinión pública (Gunn, 1983 y 1995), en este trabajo nos centraremos en Francia, y de modo particular en la figura de Jacques Necker (1732-1804).

Como recuerda Kaufman (2004: 91), la Encyclopedie, publicada en Francia en 1765, no mencionaba la opinión pública, aunque sí incluyó la voz "opinión”. En efecto, la Encyclopedie, situando la opinión en el dominio de la Lógica, la definía como "una creencia fundada sobre un motivo probable, o un juicio del espíritu dudoso e incierto"; o mejor como "el consentimiento que da el espíritu a las proposiciones que no le parecen verdaderas a primera vista y que no se derivan como consecuencia necesaria de las que llevan consigo la impronta de la verdad" (Encyclopedie, Vol. 11: 506; Baker, 1990: 167).

En cambio el sintagma "opinion publique" sí aparece, en 1789, en la Encyclopedie Mehodique (Baker, 1990: 161). En esta obra se prescindió de la voz ‘opinión’ en las secciones de carácter filosófico, y en su lugar se introdujo la voz "opinion publique” en la sección dedicada a los temas de la administración pública. Baker

$26 \mid n^{\circ} 7$ | doxa.comunicación 
(1990: 168) escribe que “en el espacio de una generación, la vacilante lámpara de la 'opinión', se transformó en la infatigable luz de la 'opinión publica', la Luz del tribunal universal ante el que tanto los ciudadanos como los gobiernos tendrían que comparecer”.

La influencia de Jacques Necker en esta transformación, aunque quizás en un plano más pragmático que teórico, fue decisiva (Bauer, 1914: 17). Speier (1950: 379) lo consideró como "el primer autor que popularizó la noción y el término ‘opinión pública’ en toda Europa, en vísperas de la Revolución Francesa”. Y Blondiaux (1998: 35, n. 10), advirtiendo que "una leyenda tenaz, ha pretendido que es Rousseau quien primero utiliza la opinión pública en su sentido moderno", afirma (1998: 39) que "es preciso ver más que una coincidencia en el hecho de que Necker haya sido a la vez el primer teórico francés de la opinión pública y el primer hombre de gobierno, via la decisión tomada en 1791 de publicar una Compte rendu sur l'etat général des finances de la France, para romper el secreto del ejercicio del poder y levantar acta simbólicamente de la existencia de esta opinión pública".

\section{La opinión pública en la vida de Necker}

Necker no sólo reflexionó sobre la opinión pública, sino que, además, vivió con ella una relación tormentosa. Celebrado por unos, calumniado por otros, "pero con la mayor frecuencia encerrado en la tumba de un pesado olvido" (Bredin, 2000: 40), Necker ha recibido afortunadamente una atención reciente, que ha clarificado sus contribuciones en este dominio (fundamentalmente: Baker, 1990; Blondiaux, 1998; Bredin, 1999 y 2000; Burnand, 2004; Gunn, 1995; Jaume, 2004; Ozouf, 1987; y Sheehan, 2002). Ciertamente, estas investigaciones recientes han arrojado una luz formidable sobre la biografía, la personalidad y las ideas del banquero y político ginebrino sobre la opinión pública; sin embargo, a pesar de las páginas que Grange dedica a las ideas religiosas de Necker (1974: 517-614), y de la alusión que hace Bredin (2000:31) a su obra $D e$ l'importance des opiniones religieuses (1788) no se ha destacado que, precisamente en esta obra, se completa el pensamiento de Necker sobre la opinión pública.

Necker se remite ya a la opinión pública en su primera obra de 1769, Réponse au Mémoire de M. l'abbée Morellet sur la Compagnie des Indes (1820, T. XV: 131), al decir que solicita para sus propuestas "la atención de estos hombres 'honnêtes et non prévenus' cuyo juicio severo e imparcial fija antes o después la opinión pública”. A partir de este texto sus referencias a la opinión pública son continuas, aunque se trate de ella de un modo especial en De l'administration des finances en France (1784) y en De l'importance des opinions religieuses (1788). De todos modos, la consideración de la vida de Necker, en relación con su obra escrita, nos permite ver ciertos cambios, no sólo de orden cognitivo, podríamos decir, sino también de carácter afectivo. 
Bredin (2000: 32) subraya cómo inicialmente Necker pensaba acerca de la opinión pública en términos de una opinión ilustrada, la opinión de los asistentes a los salones distinguidos de la sociedad parisina; pero cuando una parte de esa opinión se volvió contra él, Necker, sin negar su poder, se dirigió a "una opinión pública más amplia, la de toda una nación". Por esto afirma Egret (1975: 61) que "Necker fue ciertamente hombre de una camarilla, pero su ambición era más alta. Era la opinión pública nacional lo que quería conquistar”. Y, todavía más, Necker intentó más tarde 'conquistar' para sí la opinión europea, mientras que se refería con matices melancólicos a aquella opinión pública con la que mantuvo tan estrechas relaciones de amor-odio. En Sur l'administration de M. Necker, par lui même (1791), Necker comienza declarándose víctima de una serie de injusticias de las que hay pocos precedentes en la historia, y pasa a decir enseguida: "No sé por qué la opinión pública ya no es lo que era ante mis ojos. El respeto que le he rendido religiosamente, ese respeto se ha debilitado, cuando la he visto sometida a los artificios de los malvados, cuando la he visto temblar ante las mismas personas que en otro tiempo ella hacía comparecer ante su tribunal para condenarlas a la vergüenza, y marcarlas con el sello de su reprobación” (Necker, 1820, T. VI.1: 3-4).

Nacido en Ginebra y trasladado a París en plena juventud, para trabajar en la banca, con el apoyo del suizo Isaac Vernet, Necker había logrado la dirección del banco y una fortuna personal en 1765, a sus 33 años. En el reinado de Luis XV, prestó dinero al gobierno francés, y pasó además a ser miembro de la Compagnie des Indes francesa (1769), actuando también como embajador de Ginebra en París desde 1768. En 1770 era ya bien conocido, y gozaba de cierta popularidad ante la opinión pública ilustrada; una "conquista (que) no es fruto del azar; (sino que) estaba mantenida por una hábil campaña de propaganda” (Burnand, 2004: 16), impulsada por su mujer, Suzanne, que mantiene todos los viernes una tertulia en su salón. A esa tertulia acudían los ilustrados que contribuyeron a extender la popularidad de Jacques Necker. En una época-la segunda mitad del siglo XVIII en la que las celebridades se forjan en las tertulias y en los periódicos (que se alimentan precisamente de las tertulias), la tertulia de la señora Necker era un trampolín excelente (Egret 1975: 21-29 y 60-61; Bredin, 1999: 43-56).

Cuando Necker se retiró del banco a los 40 años (1772), comenzó a escribir sobre problemas económicos y financieros del momento. Y cuando en 1776 le llamaron para dirigir las finanzas del Estado, sustituyendo a Turgot, aunque sin el título de Controleur Générale, por ser extranjero y protestante, ya había escrito el Éloge de Jean-Baptiste Colbert en 1773, y Sur la législation et le comerce des grains en 1775 (Necker, 1820, T. XV: 127 y ss.; T. XV: 3 y ss.). El primero le valió el premio y apoyo de la Academia francesa, "uno de los lugares en los que se difunde, si no es que se forma, una opinión pública" (Viala, 1997: 6). Este escrito, que trata además del papel del Controleur Générale des Finances, es en buena medida el retrato robot del ministro ideal de fi- 
nanzas (o de hacienda): parece como si fuera la presentación de su propia candidatura por parte de Necker, que se muestra como el hombre capaz de manejar la situación; en 1778 fue requerido para hacerse cargo de la hacienda. No interesa aquí la política financiera seguida por Necker; lo que interesa para nuestro propósito es que él sabe que la opinión pública le apoya: como escribió su hija, Madame de Staël: "su fuerza (...) consistía en su popularidad".

Speier (1950: 380) ha apuntado que "la gran contribución de Necker a la historia de la opinión pública no fue tanto lo que escribió sobre su poder, sino más bien su importante innovación de publicar informes financieros (compte rendu) de tal modo que los aciertos y fallos de la política gubernamental en este campo pudieran ser valorados públicamente". Como dice Habermas (1980: 89-90), Necker "fue el primero en conseguir que la publicidad políticamente activa abriera una brecha en el sistema absolutista” (...). Desde la Compte rendu de Necker ya no es posible inutilizar la eficacia de esa publicidad en sus funciones políticas, sólo es posible oprimirlas". En la Compte rendu au roi (1781), en la que Necker se remitía a la experiencia inglesa -de la que tanto aprendió en el viaje que había hecho a Inglaterra con su familia, pocos años antes, no hay, en efecto, una reflexión sobre la opinión pública, aunque se aluda ocasionalmente a "la opinión"; Necker (1820, T.I: 1-2) subrayaba, desde luego, que "la publicidad de las cuentas y su autenticidad (podían) ser infinitamente útiles para el bien de los asuntos" del monarca; mientras que "las tinieblas y la oscuridad (favorecerían) la indigencia”. No obstante, aunque el acto concreto de publicación de la Compte rendu tenga una importancia decisiva, la posterior publicación de De l'administration des finances en France extendió por muchos países las ideas de Necker sobre la opinión pública, como veremos enseguida.

Ciertamente la cuestión de la reputación, o el amor de la consideración y la alabanza, como solía escribir Necker, se encuentran en la base de sus ideas sobre la opinión pública, en una línea próxima a la de Locke, cuando trata de la ley de la opinión, pero la relevancia política de las ideas y las acciones de Necker es también evidente. Se hace especialmente explícita en el informe confidencial que el Conde de Vergennes escribió a Luis XVI, en el que prevenía al monarca en estos términos: "Si la opinión pública del señor Necker llega a ganar ascendencia, su Majestad debe prepararse para ver que mandan quienes antes obedecían, y obedecerán quienes mandaban antes" (Tönnies, 1922: 385).

La publicación de la Compte rendu constituyó un acto innovador, destinado fundamentalmente a tranquilizar al público, para asegurarse el crédito. Pero Necker no pretendía que "que la voluntad general del público debiera ocupar el lugar del gobierno. Necker representa una fase de transición entre las visiones de la opinión pública pre-democrática y democrático-revolucionaria” (Speier, 1950: 380). La publicación del informe de Necker, cuando ya llevaba cinco años dirigiendo la hacienda francesa, "fue una de las principales apela- 
ciones de Necker a la opinión pública; y la respuesta a esta apelación fue impresionante". Este hecho reconoce al público el derecho de ser informado y lo sitúa en disposición de juzgar” (Burnand, 2004: 22-23). Cuando diez años más tarde Necker publicó Sur l'administration de M. Necker vu par lui même (1791, T.VI.1: 16), subrayó la importancia “de la determinación tomada por el rey de dar la mayor publicidad al estado de las finanzas; (el rey) fundó así la confianza sobre la base más sólida; (y) llamó a la nación al conocimiento y examen de la administración pública, y así convertía los asuntos de Estado, por primera vez, en una cosa común".

La Compte rendu se convirtió en un éxito editorial tan resonante, y no sólo en Francia (Grange, 1974: 35-36), que el propio editor no pudo responder a la demanda, y los interesados llegaron a organizar lecturas públicas con los escasos ejemplares disponibles. Pero el informe le suscitó a Necker muchas enemistades que iniciaron su campaña de descrédito mediante conversaciones, publicaciones panfletarias y, en ocasiones, amenazas personales ${ }^{1}$ (Popkin, 1989: 356 ss.; Egret, 1975: 162 y ss.).

Necker fracasó en su propósito de ser miembro del consejo del rey, y dimitió. El anuncio de la dimisión se difundió por el país el 20 de mayo de 1781, y suscitó un gran apoyo al ginebrino, al que se consideró como "un mártir de la verdad y de la libertad" (Burnand: 2004: 26). Esa derrota política fue prácticamente una victoria, si tenemos en cuenta las numerosas manifestaciones de apoyo que recibió. Necker no volvió a ser el responsable de la hacienda francesa hasta 1788, pero en esos años que transcurren hasta su regreso a la corte escribe tres de las obras especialmente importantes que contienen sus ideas sobre la opinión pública: De l'administration des finances en France y De l'importance des opinions religieuses, ya mencionadas, y los Nouveaux éclaircissements sur le Compte rendu au roi (1788).

Durante su segundo mandato, iniciado en agosto de 1788, Necker experimentó el apoyo vibrante de la opinión pública. En una situación económicamente adversa, Necker consideró que se requerían soluciones rápidas para hacer frente al desastre, y planteó varios cambios en la política. En su intervención ante los estados generales, convocados con anterioridad, y que se reunieron en Versalles en mayo de 1789, Necker pronunció un discurso tedioso, pero mantuvo su popularidad; el Tercer Estado lo consideraba como su aliado principal frente a la corona (Burnand, 2004: 35). Necker esperaba que Luis XVI anunciara varias reformas en la sesión regia del 23 de junio de 1789, con lo que, a su juicio, ganaría a la opinión pública, a la que también hace frecuentes referencias en su obra posterior De la Révolution française (1820: T. IX y T. X),

\footnotetext{
1 Beach (1958: 323) refiere que el 10 de julio de 1789 el Conde de Artois se enfrentó a Necker y le dijo a bocajarro: “¿A dónde vas, traidor extranjero? ¿Es a eso a lo que perteneces, a la inoportuna burguesía? O te vuelves a tu pequeña ciudad, o te mataré con mis propias manos".
} 
que se publicó en 1796. Pero Luis XVI cambió de opinión, y Necker decidió ausentarse de la sesión regia, lo que provocó varias consecuencias inmediatas: la ocupación de Versalles primero, la petición de Luis XVI a Necker para que no dimitiera, y su despido -en contraste con esto el 11 de julio de 1789, pidiéndole que abandonara el país de un modo clandestino (Staël Holstein, 1820: CCLIV-CCLXIII). El 12 de julio, mientras Necker abandonaba Francia, la noticia de su dimisión actuó como un detonante que provocó la cólera; y las turbas ocuparon la Bastilla de un modo simbólico. El nombre de Necker estaba en todas las bocas como sinónimo de libertad, él es la víctima gloriosa de la arbitrariedad (Bredin, 2000: 34). El 16 de julio el rey, para calmar los ánimos, volvió a llamarlo. Necker recibió en Basilea, el 23 de julio, la carta del rey y la de la Asamblea Nacional, que pedían su regreso, y regresó a París: "El viaje de M. Necker, de Basilea a París, fue una marcha triunfal. Las aclamaciones más vivas resonaban a su entrada en cada ciudad; el pueblo se estrechaba en torno a él; se desenganchaban los caballos; ciudadanos de todas las clases arrastraban su carroza, a los gritos de 'vive M. Necker!' las campesinas se ponían de rodillas cuando pasaba: jamás un ministro ha inspirado tales arrebatos" (Staël Holstein, 1820: CCLXIX). El 29 de julio Necker fue recibido triunfalmente en la Asamblea Nacional. Y el 30 es el día de su máxima popularidad; en ese día 30 de julio de 1789, como ha escrito Bredin, "Necker y el espíritu público celebran sus últimas nupcias" (2000: 35). El entusiasmo anuncia la caída, rápida por cierto.

"La pérdida del favor público es seguramente uno de los rasgos que marcan el tercer ministerio de Necker" (Burnand, 2004: 41). La tensión existente en Francia no soporta las actitudes moderadas; y Necker era fundamentalmente un moderado, que se encontró entre dos fuegos: el de los partidarios del antiguo régimen, y el de los nuevos líderes. Si antes había quienes le denigraban, pero gozaba del favor del público, a partir de la segunda mitad de 1789, y sobre todo en 1790, la tendencia se invierte. Comienza su impopularidad, que se manifestará después en la aversión y la indiferencia que le rodea cuando abandona París en septiembre de 1790. Los periódicos y los libelos le atacan, y estos últimos difunden la imagen de Necker como alguien que ha engañado a los franceses. Marat es el más activo; aprovechando que la política económica no tiene un éxito inmediato, presenta a Necker "como a un charlatán peligroso que por fin ha sido desenmascarado". Necker abandona París, acompañado de su mujer, el 8 de septiembre de 1790: "había vuelto a Francia como salvador de la nación. Un año más tarde, su popularidad está arruinada, y abandona el reino por la puerta trasera" (Burnand, 2004: 43-45).

No puede sorprender que, de regreso a su palacete de Coppet, al escribir Sur l'administration de M. Necker par lui-même (1820, T.VI.1:3), obra que publicó en 1791, se le escapara una queja amarga: "En fin, no sé por qué la opinión pública no es a mis ojos lo que era antes. El respeto que le he rendido religiosamente, este 
respeto se ha debilitado, cuando la he visto sometida a los artificios de los malvados, cuando la he visto temblar ante los mismos hombres a los que anteriormente ella había hecho comparecer ante su tribunal, para condenarles a la vergüenza, y marcarles con el sello de su reprobación".

Pudiera ser que el debilitamiento de la confianza de Necker con respecto a la opinión pública fuera tan sólo un desfallecimiento momentáneo, provocado por la experiencia reciente de la hiriente indiferencia que palpó al abandonar Francia. Bredin (1999: 272) atribuye a Necker un texto sugerente: "La opinión pública es más fuerte y más ilustrada que la ley; es más fuerte porque está presente por doquier, ya que ejerce su imperio en la sociedad y hasta en el seno de las familias; (y) es más ilustrada porque si la ley puede ser la obra de un solo hombre que se equivocaría, la opinión es el resultado de los pensamientos de las naciones y de los siglos". Y sitúa el texto en una obra póstuma de Necker², que recoge manuscritos reunidos por su hija, Madame de Staël, que están sin datar³.

\section{Las ideas de Necker sobre la opinión pública}

Jaume (2004: 33ss.) argumenta que si por 'concepto' se entiende "una definición unívoca, exportable del contexto histórico en que nace y apta para entrar en un sistema teórico o una doctrina”, no podríamos encontrar en Necker un concepto de opinión pública. Necker entendería la opinión pública como una especie de idea-fuerza, en el sentido de Alfreed Fouillée. Realmente sería demasiado pedirle a Necker un concepto riguroso de opinión pública cuando, después de más de dos siglos y medio, persiste la ambigüedad (LópezEscobar, 2007) y la incertidumbre ante ese fenómeno (Price, 1992). Sin embargo, la vida y las reflexiones de Necker -y esto a pesar de su relativa desilusión tras su último período de servicio a la monarquía francesaconfirman su relevancia en el proceso de situar a la opinión pública en el centro de la vida política, y eso no sólo en Francia.

Aunque efectivamente Necker hace alusiones a la opinión pública desde su primera obra, expuso lo más sustancial de su pensamiento en De l'administration des finances de la France (1784). "La publicación de este

\footnotetext{
2 Necker, Jacques (1820): Oeuvres complètes de M. Necker (publiées par M. le Baron de Staël, son petit-fils), reimpresión de Adamant Media Corporation, 2003. Son quince tomos, que en el texto se citan con una T. seguida del tomo y volumen correspondiente.

3 Al buscar, como es usual, las fuentes originales, no me ha sido posible clarificar una observación que hace Burnand (2004: 46), cuando afirma que Necker, al final de su vida, recuperó una "gran estima por su antiguo ídolo", y cita la frase transcrita, supuestamente recogida en sus Pensées detachées, "publicados por su hija en 1805" (sic). Burnand atribuye la referencia a Bredin (1999: 372). Efectivamente Bredin (1999: 401) cita ese texto atribuyéndolo a los Manuscrits de M. Necker publiées par sa fille: Pensées detachées en 1804. He manejado las Oeuvres complètes de M. Necker, que recogen el texto de 1804 (T.XV: 203-320), y no he podido encontrar en él esa frase tan sugestiva.
} 
libro se convirtió inmediatamente en un acontecimiento europeo"; pues cuando una edición de 4.000 ejemplares se consideraba en la época un éxito editorial, del libro de Necker se vendieron cientos de miles, a los que habría que añadir las traducciones a un buen número de idiomas diferentes del francés (Grange, 1974: 38-52). El libro se convirtió enseguida no sólo en el más vendido en Francia, sino en el best-seller de todo el siglo XVIII en toda Europa.

Necker se ocupó de la opinión pública, fundamentalmente, en la larga introducción (125 páginas), y en el capítulo final, "Et dernier", de la obra4 ${ }^{4}$ En esos textos utilizó con gran profusión la expresión 'opinion publique'. Como otros contemporáneos, consideró la opinión pública como un tribunal poderoso, más que como una ley (Baker, 1990: 25). Precisamente los textos más famosos de esta obra son los que dicen: "El espíritu de sociedad, el amor de la consideración y de la alabanza, han erigido en Francia un tribunal ante el que todos los hombres que han llamado la atención de los demás, están obligados a comparecer: en él la opinión pública, como desde lo alto de un trono, distribuye premios y coronas, hace y deshace las reputaciones" (Necker, 1820, T. IV. 1: 47); "la mayoría de los extranjeros, por motivos distintos, apenas llegan a hacerse una idea justa de la autoridad que ejerce en Francia la opinión pública: difícilmente entienden lo que es un poder invisible, que sin tesoros, sin guardia y sin ejército, promulga leyes en la ciudad, en la corte y en los palacios de los reyes" (Necker, 1820, T.IV.1: 50). Necker considera que ese poder de la opinión pública es mucho más débil "en otros países y bajo gobiernos diferentes", y añade que "las naciones reblandecidas por el clima del sur, demasiado ocupadas en todos los placeres de los sentidos, no querrían el yugo de la opinión pública" (T. IV. 1: 49).

Sin duda la experiencia inglesa influyó poderosamente en sus planteamientos; pues a partir de ella establece Necker la conexión entre la publicidad sobre el estado de las finanzas (por ello publicó la Compte rendu, que introdujo "una nueva era en las finanzas"; T. IV. 1: 88), la solidez del crédito y la necesaria consideración de que ha de gozar el responsable de aquellas. "La publicidad del estado de las finanzas-dice-abre una vía simple al establecimiento invariable del crédito; y este crédito es hoy una de las fuentes más seguras del poder político" (T. IV. 1: 87).Y también: "Entre todos los que aparecen en el escenario del mundo, es sobre todo el ministro de hacienda el que debe tratar con el mayor cuidado a la opinión pública: desgraciado si la desdeña, pero aún más desgraciado el Estado..." (T. IV. 1: 53); el ministro de hacienda es “aquel que más necesita de la opinión”, pero no para su beneficio o satisfacción personal, sino porque de ello depende la gestión de los caudales públicos (T.IV.1: 47); es el ministro que tiene "necesidad de la opinión en todo instante" (T. IV. 1: 99).

\footnotetext{
${ }_{4}^{4}$ La distribución de los capítulos es distinta según se use la edición de 1785 en tres volúmenes (Lausanne), o la edición de las obras completas de Necker, de 1820. Utilizaré la paginación de las obras completas.
} 
La autoridad de la opinión pública parecía novedosa; resultaba desconocida en la medida que los espíritus, "divididos en facciones" que sólo odiaban o amaban, "no podían reunirse bajo las banderas más tranquilas de la estima y de la opinión pública”. Circunstancias diversas habían demorado su imperio, pero -escribe Necker- "el poder de la opinión pública, favorecido por diversas circunstancias ha crecido sucesivamente, y sería hoy difícil destruirla: ella reina sobre todos los espíritus, y los propios Príncipes la respetan siempre que no son arrastrados por pasiones demasiado grandes, unos la cuidan voluntariamente, por la ambición que tienen del favor público, y los otros menos dóciles también le están sometidos, sin advertirlo, por el ascendiente de quienes les rodean" (T. IV. 1: 47-49).

Para Necker la opinión pública es una fuerza tranquila, racional, sólida, que no debe confundirse "con esos movimientos efímeros que, con frecuencia, solo se dan en ciertas sociedades y en ciertas circunstancias". Por ello afirma que "el hombre capaz de una gran administración", en lugar de prosternarse ante ese tipo de movimientos efímeros, ha de saber "desdeñarlos, para permanecer fiel a esta opinión pública en la que todos sus caracteres son importantes, y que la razón, el tiempo, y la universalidad de los sentimientos, son los únicos que tienen el derecho de consagrarla" (T. IV. 1: 56). Esta idea de la lenta consolidación de la opinión pública se repite también cuando Necker escribe que el ministro de hacienda "nunca abandonará la estima del favor; y (que) amará, aun más que la alabanza, las bendiciones secretas del pueblo que apenas oirá, y esta opinión pública que se forma lentamente, y cuyos juicios hay que esperar con paciencia" (T. IV. 1: 19).

Indudablemente, en el momento en que escribe De l'administration des finances en France, Necker tiene una visión idílica, entusiasta de la opinión pública; afirma que ella ejerce su imperio -el más noble y razonablereinando sobre "los hombres, para alimentar en ellos el amor a la gloria verdadera, para excitarles a grandes cosas por el honor y la alabanza, y para alejarles de la bajeza y de la vileza por el temor al menosprecio y a la vergüenza" (T. IV. 1: 52). Para él "es el ascendiente de la opinión pública, el que con frecuencia, más que ninguna otra consideración, pone obstáculos en Francia al abuso de la autoridad" (T. IV. 1: 52-53). La opinión pública, que "sirve al mismo tiempo de estímulo y de recompensa, puede además convertirse en un conductor fiel” (T. IV. 1: 56). El propio rey sería mal servido por quienes no contaran con la opinión pública; una opinión que, además, ilustraría al monarca sobre las cualidades de sus inmediatos servidores; de tal manera que detener la opinión pública, sofocar su voz, significaría privar al rey de su consejero más ilustrado, imparcial e íntegro. Sin duda sería más cómodo gobernar en un país en el que la opinión pública estuviera muerta, pero las alabanzas que surgieran serían "un ruido de esclavos, y no un sentimiento ilustrado" (T. XV: 277, Pensées detachées, LXX). 
Pero Necker, aparte de distinguir la opinión pública de los 'movimientos efímeros', manifiesta que ésta no es una especie de producto social espontáneo; sino que requiere ilustración ${ }^{5}$.

Y como advierte algunos síntomas de deterioro social, invoca a la opinión pública, para que ésta estimule las acciones plausibles; reiterando que para eso "es preciso (...) sostener esta opinión; es preciso ilustrarla, es necesario llamarla en ayuda de la ideas que interesan verdaderamente a la felicidad de los hombres" (T. V. 2: 613-616).

Necker no ha reducido su estima por la opinión pública en 1788, cuando escribe, en vísperas de su regreso a la corte de París, los Nouveaux éclaircissemens sur la Compte Rendu au Roi en 1781 (1788, T. II. 2: 600): "una verdad bien cierta - escribe- es que, en todas las circunstancias, conocidas y desconocidas, le conviene a la nación francesa ocuparse de la opinión pública, mantener su ascendiente, y acordarse de sus beneficios". Pero, inmediatamente, introduce un caveat, que es indicativo de que sabe que puede manipularse ${ }^{6}$.

Recomienda a los príncipes que no presten oídos a aquellos que "querrían servirse de la opinión pública", los cuales querrían degradarla precisamente para vengarse de su enemistad. "Que no les crean, escribe, cuando a menudo les oigan decir que la opinión pública fue siempre importuna para la autoridad; esta insinuación peligrosa no tiene más que una chispa de verdad". Necker señala que los ministros podrían llegar a cercar al monarca, impidiéndole conocer la verdad, de tal modo que haciendo sospechoso "el ruido sordo, pero constante, de la opinión pública, el trono de los reyes se encontraría como en medio de un desierto". En cambio, si el monarca pudiera sentir personalmente la acción de la opinión pública, "el cerco que (ésta) forma (...) en torno al trono será el menos molesto de todos; y es cuidando esta opinión, respetándola, al menos en los intereses más delicados, como Francia ha presentado, por bastante tiempo el espectáculo concreto de un gobierno prudente y generoso" (T. II. 2: 600-602).

\footnotetext{
5 “...si es importante multiplicar los medios de instrucción para todos aquellos que deberán participar un día en el gobierno, no es menos esencial ilustrar al tribunal ante el que serán todos llamados a comparecer, y este tribunal es el de la opinión pública. Que no haya duda, son las luces generales las que antes o después vienen a ser el principio activo del bien del Estado; y no existirá nunca salvaguarda potente contra los errores y los falsos sistemas, en la medida que la opinión pública sea débil en sus juicios, incierta en su ciencia, y distraída en su atención".

6 "pero para asegurar su asistencia es preciso abstenerse siempre de hacer de la opinión pública un instrumento del capricho o de la tiranía; porque si llega a agitarse su cetro con indiferencia, si se llega a desanimar a quienes la cultivan, y a aquellos que honran su tribunal, se correría el riesgo de perder, se correría el riesgo de debilitar el único poder que estará constantemente en armonía con nuestras costumbres y con nuestro espíritu social; el único poder con el que se introducen recompensas preferibles a las dignidades y a la fortuna; el único con el que se puede, en nombre de la justicia y del honor, dirigir a quienes administran, y doblegarlos, antes o después, al yugo de la razón, cuando pretenden liberarse de ella; el único poder, en fin, que no es rival del trono, porque secunda las intenciones benéficas del soberano, haciendo la guardia, por él, en torno a quienes buscan sorprenderle".
} 
Ocasionalmente, en contraste con la valoración positiva, volvemos a percibir, en otros pasajes de su obra, cierta ambivalencia sobre la opinión: "He visto a la opinión de la sociedad abusar de su poder. Se imponía a los ministros y esto muchas veces fue algo bueno; pero en varias ocasiones habría querido burlarme de ella, y seguramente lo habría intentado, si hubiera tenido una fuerza personal", dice uno de sus manuscritos publicados en Pensées detachées (T. XV: 310).

\section{Opinión pública, moralidad, religión}

Madame de Staël, la hija de Necker (1820: 98), escribió que “después de sus deberes religiosos la opinión pública era lo que más le ocupaba [a su padre]; [Necker] sacrificó la fortuna, los honores, todo lo que buscan los ambiciosos, a la estima de la nación; y esta voz del pueblo, todavía no alterada, tenía para él algo de divino. La menor sombra sobre su reputación era el mayor sufrimiento que podían producirle las cosas de la vida. El objetivo mundano de sus acciones, el viento de tierra que le hacía navegar, era el amor de la consideración". Esta afirmación de Madame de Staël plantea la cuestión de si Necker, además de establecer una relación entre la política y la opinión pública, llegó a relacionar también la opinión pública con la religión y la moral.

Pienso que sólo si se presta atención a De l'importance des opinions religieuses, se puede tener un conocimiento completo del pensamiento de Necker sobre la opinión pública. Quizás en este libro es donde precisamente Necker hizo más referencias a la opinión pública. Como él mismo recuerda (refiriéndose indudablemente a De la administration des finances en France), ya habló "en otra obra de la opinión pública"; pero ahora, cuatro años más tarde, considera a la opinión pública desde una perspectiva diferente. Los capítulos II y VII son los relevantes en este momento: en el primero se plantea un posible paralelismo entre la influencia de las ideas religiosas y la influencia de las leyes de la opinión; y en el segundo trata de las opiniones religiosas y la opinión pública en sus relaciones con los soberanos. Bredin (2000:31) subraya que la publicación (1788) de De l'importance des opiniones religieuses, no interrumpió la relación apasionada de Necker con la opinión pública. Pero en esta obra, que es un largo alegato a favor de la religión -"que puede y debe ser la auxiliar del gobierno de los hombres” - Necker señaló los peligros del espíritu irreligioso del siglo XVIII.

La primera cuestión es en qué medida la opinión pública tiene fuerza suficiente "para contener a los hombres". Inmediatamente surge un paralelismo: el que podemos establecer entre el tribunal de la opinión pública y el tribunal de la propia conciencia. Si opinión pública es un tribunal, también lo es la conciencia: "Oh conciencia!, escribió Necker en una de los manuscritos publicados por su hija. Primer tribunal en nuestro círculo intelectual, primer tribunal en el imperio moral del mundo...” (T. XV: 290, Pensées detachées XCII).

$36 \mid n^{\circ} 7$ | doxa.comunicación 
Necker afirma resueltamente que, sin las ideas religiosas, la regla de la opinión pública resulta deficiente. Ella ejerce su autoridad en un espacio sumamente circunscrito; porque está llamada "a juzgar a los hombres cuyo rango, empleo y trabajos tienen algún brillo en el mundo: la opinión pública es una aprobación o censura ejercida en nombre del interés general; así ella debe aplicarse únicamente a las acciones y a los discursos que tocan a este interés de una manera más o menos directa”. Pero la gran mayoría de los ciudadanos son "independientes de la opinión pública, o al menos no experimentan su severidad (...)”. Esto significa que son diferentes "el ascendiente particular de la opinión pública y la influencia general de la moral religiosa”. La conciencia tiene una jurisdicción más amplia que la opinión pública, pues la moral religiosa tiene una influencia "universal, constante y siempre igual".

La opinión pública que, podríamos decir, presta su atención a lo sobresaliente, ignora todos los esfuerzos escondidos, regidos y acompañados siempre por la moral. La primera, que distribuye bienes "cuyo principal valor se fija en las comparaciones, contrastes y rivalidades, atrae a menudo sobre sus favoritos el soplo venenoso de la envidia y se duda entonces, del precio real de sus beneficios". La moral religiosa, por contraste, "no mezcla ninguna amargura con sus recompensas, otorga la dicha en la oscuridad; y, como dispone de tesoros para todo el mundo, la parte que concede a unos no quita nada a los otros" (T. XV: 86).

Por otra parte, y siguiendo con el símil del tribunal, la opinión pública es un juez más falible: "se equivoca a veces en sus juicios; porque en medio de este vasto recinto en el que está erigido su tribunal, a veces tiene dificultades para distinguir el mérito verdadero y el brillo que le sigue, los falsos colores de la hipocresía"; en cambio, "la moral religiosa domina en el fondo de los corazones, y coloca un vigilante en el fondo de los corazones, que ve a los hombres más de cerca que por sus acciones, y que así no se puede equivocar ni sorprender" Además, hay momentos "en que la opinión pública se debilita, tiempos en los que se hace ruin, y en que, dominada por un espíritu servil, busca culpas para los oprimidos, y atribuye grandes pensamientos a los hombres poderosos, con el fin de poder, sin vergüenza, abandonar a los primeros y celebrar a los segundos" (T. XV: 86-87). No es ese el caso de la moral.

También reconoce Necker que puede ser fácil "someter a los seres humanos a una opinión dominante, cuando ellos mismos y quienes les gobiernan aúnen todos sus esfuerzos para alcanzar tal fin”; pero tal opinión podría ser viciosa. Por ello, y prosiguiendo su reflexión, Necker pide "en nombre de la razón, en nombre de la política, en nombre de la filosofía”, respeto para las ideas religiosas, pues son ellas precisamente las que "dan firmeza a la opinión pública y..., más o menos oscuramente, dirigen y contienen sus diversos ramales". Si se obrara de otro modo, y se quisiera "fundar todo sobre cálculos mundanos, estos mismos cálculos destruirían todo; y una vez que la moral haya perdido su gran apoyo, en vano se intentaría sostenerla con 
el andamiaje de las leyes, y por los vanos esfuerzos de una opinión carente de guía”. De no ser así, el disfraz y la simulación se convertirían de pronto en "una ciencia necesaria, una defensa legítima", convirtiendo la convivencia en un "simple juego de unos contra otros" (T. XV: 99).

Necker retoma esta idea en el capítulo VII, que trata "de las opiniones religiosas en sus relaciones con los soberanos": "como lo he mostrado antes -escribe-, el poder de la opinión pública se debilitaría infinitamente, si los principios morales que sirven de guía a esta opinión no tuvieran una idea religiosa como ligazón y apoyo" (T. XV: 165). La moral religiosa sigue siendo capital, y "habría un gran peligro en apoyarse tanto sobre el poder de la opinión pública, que se viniera a considerarla como un freno capaz de reemplazar ante los príncipes la fuerza contenedora de la moral religiosa" (T. XV: 166).

Necker imagina "una época en la que, por la degradación sucesiva de los caracteres, la opinión pública no indicara el rumbo", un país, o una ciudad en la que "la codicia apareciera como triunfante, y en donde cada uno se manifestara en búsqueda de la fortuna que se adquiere por la intriga y por los vicios”; en una situación semejante solo la moral, aquella que conviene a todos los tiempos y a todas las circunstancias, es "la que puede resistir a las revoluciones de los hábitos y de las opiniones, de la que la historia nos proporciona ejemplos, y a los que los hombres son susceptibles en todas partes" (T. XV: 169).

Finalmente, Necker vuelve a la idea de la orientación de la opinión pública: son precisamente los príncipes quienes, "por la elevación de su rango, y por su influencia sobre las costumbres nacionales, se encuentran en esta posición única y singular en la que están más llamados a dirigir la opinión pública que a recibir de ella instrucciones y estímulos". Por ello considera que "hay que desear que un monarca tenga principios que broten de su corazón, y que dependan de su reflexión, los únicos capaces de darle en todo momento una fuerza que le sea propia, y un valor que le pertenezca: Es preciso que el príncipe sea su primer juez; es preciso, por decirlo de algún modo, que él mismo tome su altura; es preciso que una moral sublime mantenga en el fondo de su alma un modelo ideal de perfección, con el que pueda enlazar sin cesar la opinión del mundo y los juicios de su propia conciencia" (T. XV: 170-172).

Por último, quizás hablando por su propia herida, alude Necker a los ministros, haciendo una especie de alegato contra quienes considera servidores indignos del monarca. Estos pueden lograr debilitar la opinión pública, "atribuyendo este movimiento a pasiones particulares, llamando cábala a la indignación contra el vicio". Una consideración de este tipo le lleva a afirmar la "absoluta necesidad de una moral activa y dominante" (T. XV: 173): "los ministros sin virtud, arguye, son más temibles que los soberanos indiferentes al bien público". Estos ministros, atacados por la opinión pública "se hacen todavía más malignos en sus medios de defensa"; ellos "se aplican al mismo tiempo a adornar la inmoralidad con todas las gracias que 
pueden hacerla amable, y tratan de hacer que se odie la virtud, representándola como austera, autoritaria, insociable, y casi incompatible con nuestras costumbres y nuestras maneras". De este modo, los ministros, "libres de toda especie de principios no sólo provocan la desgracia de un país durante el período de su mandato, sino que aun alteran las fuentes primarias de la felicidad pública, debilitando en un monarca el sentimiento de sus deberes, desviándolo a veces de sus felices inclinaciones, y desanimándolo, por decirlo así, de sus propias virtudes" (T. XV: 174).

Al margen de lo circunstancial, que refleja, más o menos veladamente, la propia biografía de Necker, estas ideas no pueden marginarse, si se quiere tener un conocimiento cabal de su contribución en la causa de la opinión pública.

\section{Conclusión}

La historiografía contemporánea, que ha dirigido nuestra mirada hacia Inglaterra, tanto por lo que se refiere al desarrollo del fenómeno político de la opinión pública como al origen del propio sintagma que la identifica, ha subrayado también la importancia de Jacques Necker, como una personalidad que no sólo alentó la opinión pública, sino que se convirtió en su adalid por toda Europa. Su decisión de publicar las cuentas del Estado de la hacienda francesa, y sobre todo su libro De l'administration des finances de la France son elementos clave en ese proceso que convirtió a la opinión pública en un "héroe de la política". No obstante, las ideas de Necker acerca de la opinión pública no se agotan en esa obra. Es necesario prestar atención al conjunto de sus escritos, y de modo particular a De l'importance des opinions religieuses, para conocer su pensamiento completo. Al hacerlo se descubre un Necker que puede seguir contribuyendo de un modo relevante a las discusiones sobre la naturaleza, el origen y la significación de la opinión pública en la época contemporánea.

\section{Referencias bibliográficas}

Baker, Keith Michael (1990): Inventing the French Revolution: essays on french political culture in the Eighteenth Century, Cambridge: Cambridge University Press.

Bauer, Wilhelm (1914): Die öffentliche meinung und ihre geschichtlichen grundlagen, Aalen: Scientia, 1981.

Blondiaux, Loïc (1998): La fabrique de l'opinion: une histoire sociale des sondages, París: Seuil.

Bredin, Jean-Denis (1999): Une singulière famille: Jacques Necker, Suzanne Necker et Germaine de Staël, París: Fayard.

Bredin, Jean-Denis (2000): «Necker et l'opinion publique», en Jaume, L. (dir.): Coppet, creuset de l'esprit libéral, Aix-en-

doxa.comunicación | nº 7 
Provence: Presses Universitaires d'Aix-Marseille, pp. 25-40.

Burnand, Léonard (2004): Necker et l'opinion publique, París: Honoré Champion.

Egret, Jean (1975): Necker: ministre de Louis XVI, 1776-1790, París: Champion.

Encyclopedie, ou Dictionnaire raisonné des sciences, des arts et des métiers, par une societé des gens de lettres, 17 vols. (París, 1751-65). Vol. 11, p. 507: voz «Opinión».

Fay, Bernard (1965): Naissance d'un monstre: l'opinion publique, París: Librairie Académique Perrin.

Grange Henri (1974): Les idées de Necker, Paris: C. Klincksieck.

Gunn, J.A.W. (1983): Beyond liberty and property : the process of self-recognition in eighteenth-century political thought, Montreal: McGill-Queen's University Press.

Gunn, J. A. W. (1995): Queen of the world: opinion in the public life of France from the Renaissance to the Revolution, Oxford: Voltaire Foundation.

Habermas, Jürgen (1980): Strukturwandel der öffentlichkeit: Untersuchungen zu einer Kategorie der bürgerlichen Gesellschaft, Neuwied: Luchterhand.

Jaume, Lucien (2004): «L'opinion publique selon Necker: entre concept et idée-force », en Fernández Sebastián, Javier, y Chassin, Joëlle (coords.): L'Avènement de l'opinion publique : Europe et Amérique, XVIIIe-XIXe siècles, París: L'Harmattan pp. 33-50.

Kaufman, Laurence (2004): “Entre fiction et realité. L’opinion publique dans la France du XVIIIe siècle”, en Fernández Sebastián, Javier, y Chassin, Joëlle (coords.): L'Avènement de l'opinion publique : Europe et Amérique, XVIIIe-XIXe siècles, Paris: L'Harmattan, pp. 91-107.

Locke, John (1690): An essay concerning human understanding, Nueva York: Dover Publications, 1959.

López-Escobar, Esteban (2007): “Public Opinion: An Ambiguous Reality? A Quick Tour of ‘The Classics”, PublicOpinionPros, Febrero. Disponible en Internet [URL] http://www.PublicOpinionPros.com (consultado el 16 de marzo de 2008).

Necker, Jacques (1785): De l'administration des finances de la France, 3 vols., Lausanne: Chez Jean-Pierre Heubach et Compagnie.

Necker, Jacques (1820): Oeuvres complètes de M. Necker (publiées par M. le Baron de Staël, son petit-fils), reimpresión de Adamant Media Corporation, 2003.

Ozouf, Mona (1987): “L'opinion publique” en K. M. Baker (ed.): The French revolution and the creation of modern political culture Oxford: Pergamon Press, 1987, pp. 419-434, publicado también como “'Public Opinion' at the End of the Old Regime”, The Journal of Modern History, vol 60, 1988: Suplemento: Rethinking French Politics in 1788, pp. S1-S21.

Peters, John D. (1995): “Historical tensions in the concept of public opinion”, en Glasser, Theodore L., y Salmon, Charles T. (eds.), Public Opinion and the Communication of Consent, New York, Guilford Press, pp. 3-32

$40\left|n^{\circ} 7\right|$ doxa.comunicación 
Popkin, Jeremy (1989): "Pamphlet Journalism at the End of the Old Regime”, Eighteenth-Century Studies, vol. 22, no 3, (Special Issue: The French Revolution in Culture), pp. 351-367.

Price, Vincent (1992): Public opinion, Newbury Park: Sage.

Sheehan, Colleen A. (2002): "Madison and the French Enlightenment: The Authority of Public Opinion", The William and Mary Quarterly, vol. 59, n 4 , pp. 925-956.

Speier, Hans (1950): “Historical Development of Public Opinion”, The American Journal of Sociology, vol 55, no 4, pp. 376388.

Staël, Madame la Baronne de (1820, obra póstuma, 3ª ed.): Considérations sur les principaux événements de la Révolution Françoise, Paris: Delaunay.

Staël Holstein, A. de (1820): «Notice sur M. Necker», en Necker, Jacques: Oeuvres complètes de M. Necker (publiées par M. le Baron de Staël, son petit-fils), reimpresión de Adamant Media Corporation, 2003, T, I.1.

Tönnies, Ferdinand (1922): Kritik der öffentliche Meinung, Aalen: Scientia, 1981.

Viala, Alain (1997): “Academie Française”, en Michel Delon, director: Dictionnaire européen des Lumières, París: P.U.F. 
